\title{
STILL LIFE WITH GRANDMOTHER BEING WASHED
}

\section{Antonio Jocson}

I do not recognize her body, a white emaciation uncovered amid hospital sheets and breathing shallow, shadowless, being washed. I did not know how this was there beneath her embrace of yesterday, pain concealing itself in flesh, patiently awaiting its moment. I did not perceive the change, or the moment embellishing stopped, clarified to the white root each body has. Her sheets are drawn back more-more water being wiped across those frail shoulders, wets there in a sheen in place of powdering, pain: this will soothe, the rough cloth is at pain to say, cools better than the soft moment of talcum that beds like snow in her small white landscape, overlayering of hueless sheets, chalk on chalk: the slight differences of being, of absence. (O I am sure of a body there.) I watch her exhalations ferry here and there, lips to the air, then wherever. What pain in not now seeing where or to what moment they go, but only: the hollow white of each breath thin as the sheets she is laid upon. I want to know if this is the end of being, this biding and being felt - the washcloth moving, there now on the arm and then the hand-as this pain in her bones ticks away each moment, everything brittle and white? There is silence; there are soiled sheets upon a bed others have been, same blanket warming them. Who is this being? If this is her hand I am holding perhaps I can remember. . . 
Love is our pain; it is alive with blood in my own hand's moment, and about it nothing, nothing is white. But now we cover with sheets, with white formlessness over form and being, there like mute pain over the mouth of a moment. 